\title{
Objetivos e intereses de las insurrecciones tacneñas durante la crisis del régimen colonial español 1780-1813
}

\author{
Objectives and interests of the tacnean insurrections during the crisis of the spanish \\ colonial regime 1780-1813
}

${ }^{1}$ Efrain Choque Alanoca

\section{RESUMEn}

El presente artículo tuvo por objetivo analizar los propósitos e intereses económicos y políticos de los núcleos rebeldes que dirigieron los movimientos liberadores en el sur peruano (los corregimientos de Arica y Tarapacá) durante la coyuntura de la independencia a partir de la observación concreta de las narrativas esbozadas con motivo de las insurrecciones de José Gabriel Condorcanqui (Túpac Amaru II), Francisco Antonio de Zela, y Enrique Paillardelle en la región. Para el efecto, se realizó un estado de la cuestión realizando un análisis de contenido de estudios procedentes de fuentes nacionales e internaciones, para lo cual se utilizó una muestra criterial en base a ensayos procedentes de los representantes de las narrativas liberal y la historia crítica; por lo que se realiza en el marco de un diseño descriptivo- explicativo. La pertinencia radica en que la dilucidación de dichos rasgos constitutivos de cada movimiento permitirá diferenciar su naturaleza y sus propósitos asumidos de manera que se alcance a reconstruir con mayor objetividad el desarrollo de la independencia en el sur peruano. Las conclusiones sugieren que existe una narrativa liberal-republicana de este proceso propuesta por Rómulo Cúneo- Vidal (1921) y otra de tipo crítico-nacional en construcción sustentada por la nueva historia con Oscar Panty, entre otros. La primera vio en el movimiento tupacamarista una conjura contra el sistema, llamando a sus líderes como temibles "sanguinarios"; o el “(...) ataque de los rebeldes" al pueblo de Tacna; mientras que la nueva historia sostiene que con el movimiento de Túpac Amaru II se inicia una coyuntura de ruptura radical -como parte del movimiento nacional indígena- con el sistema colonial imperante; mientras que el de Zela constituye una rebelión autonomista-reformista y el de Paillardelle uno de signo separatista, pero estas dos últimas dentro del movimiento de liberación criollo vinculado a comerciantes y hacendados provincianos.

Palabras clave: Movimientos liberadores, objetivos e intereses, régimen colonial, sur peruano

${ }^{1}$ Dirección de Investigaciones del Instituto de Ciencias Sociales del Perú. Lima, Perú. E-mail: efrainchoque62@gmail.com. 


\section{ABSTRACT}

This article aimed to analyze the purposes and economic and political interests of the rebel nuclei that led the liberation movements in southern Peru (the townships of Arica and Tarapacá) during the period of independence from the concrete observation of the narratives outlined on the occasion of the insurrections of José Gabriel Condorcanqui (Túpac Amaru II), Francisco Antonio de Zela, and Enrique Paillardelle in the region. For the effect, a state of the question was carried out carrying out a content analysis of studies coming from national and international sources, for which a criterial sample was used based on essays coming from the representatives of the liberal narratives and the critical history; so it is carried out in the frame of a descriptive-explanatory design. The pertinence lies in the fact that the elucidation of such constitutive features of each movement will allow differentiating their nature and their assumed objectives in order to reconstruct with greater objectivity the development of independence in the Peruvian south. Conclusions suggest that there is a liberal-republican narrative of this process proposed by Rómulo Cúneo-Vidal (1921) and another of a critical-national type under construction sustained by the new history with Oscar Panty, among others. The first one saw in the Tupac Amaru movement a conspiracy against the system, calling its leaders as fearsome "bloodthirsty"; or the "(...) attack of the rebels" to the people of Tacna; while the new history sustains that with the movement of Tupac Amaru II begins a juncture of radical rupture - as part of the indigenous national movement - with the prevailing colonial system; while that of Zela constitutes an autonomist-reformist rebellion and that of Paillardelle one of separatist sign, but these last two within the movement of Creole liberation linked to merchants and provincial landowners.

Keywords: Liberation movements, objectives and interests, colonial regime, southern Peru

\section{INTRODUCCIÓN}

Se parte de la tesis central que es necesario repensar la historia de la independencia en Latinoamérica y en particular en el Perú, como parte de los grandes cambios, los nuevos escenarios y retos del presente. Esto conlleva a la dilucidación de la naturaleza del proceso, de sus etapas, sus límites y consecuencias. Sin embargo, el estudio se circunscribe al análisis de los propósitos e intereses económicos y políticos de los núcleos rebeldes que dirigieron los movimientos liberadores protagonizados en los corregimientos de Arica y Tarapacá, articulado al proceso liberador en el virreynato español en América.

Objetivamente, la independencia fue un gran movimiento y un proyecto de desarrollo nacional, que se remonta a los tiempos inmediatos a la invasión ibérica, presentando dos versiones: Primero en la versión indígena (el movimiento de liberación nacional indígena), que inicia con la rebelión de Manco Inca en el Cuzco de 1536, y que tuvo su expresión más culminante con Túpac Amaru II, en 1780. Después en la versión criolla (el movimiento de liberación nacional criollo), que inicia con la prédica de los precursores, entre ellos la "Sociedad Amantes del país", como una reacción ante la eventual reedición del movimiento tupacamarista que, por ser indígena o con dirección indígena, entraba en contradicción con sus particulares intereses (Macera, 1978). En esta segunda fase, se vislumbran dos momentos del período insurgente 18091815 en la América bajo el dominio español: El primer momento de lucha por la autonomía de los pueblos colonizados bajo el liderazgo de las Juntas de Gobierno, pero manteniendo la fidelidad al rey cautivo; y el segundo momento de lucha abierta y separatista contra el rey español y todo el aparato de opresión colonial.

Las preguntas operativas que han guiado el trabajo fueron las siguientes: ¿Cuáles fueron los objetivos ideopolíticos de la insurrección?, ¿Cuál fue la composición social del núcleo rebelde y si establecieron alianzas con otros sectores?, ¿Cuál fue el tipo de liderazgo y el sector social que asumió la dirección política y militar?, y ¿Cuáles son los alcances y límites en el proceso de la independencia en la región? 


\section{Naturaleza y carácter del proceso insurreccional}

Es cierto que la historia tradicional y liberal llamó emancipación al período de 1808-1824, por esta razón la insurrección de Túpac Amaru (1780-1782) fue excluida de sus alcances, dándole más bien un tratamiento despectivo sin categoría de erigirse en integrante de la independencia nacional. Su hispanismo era por demás evidente. Sin embargo, fue el gobierno del general Velasco Alvarado, durante las efemérides del Sesquicentenario de la Independencia (1971), que declaró oficialmente a dicho movimiento como precursora de la llamada emancipación. Esto se cumplió ya en los textos escolares y otros estudios realizados por la comisión especialmente instituida para la ocasión, con la regencia de la historiadora Ella Dunbar Temple y otros. Y a colación, se dieron leyes declarando a José Gabriel Condorcanqui y Micaela Bastidas “precursores, próceres y mártires “de la independencia en América (Cfr. decreto ley $\mathrm{N}^{\circ}$ 21705, ley $\left.\mathrm{N}^{\circ} 23225\right)$.

A pesar que el movimiento indígena fracasó, pues su programa autonomista y colectivista no se plasmó, lo cierto es que los criollos, con definida opción ideológica occidental, triunfaron militarmente e impusieron su proyecto; el proyecto de la élite que desplazó del poder a ascendientes españoles y coloniales. Tal vez el mismo día de la Capitulación de Ayacucho - Capitulación condescendiente con el vencido -, los peruanos de buena voluntad aspirantes a un orden de justicia social, habrían experimentado la sensación de un proyecto frustrado, confirmado inmediatamente después ante la evidencia que poco o nada había cambiado. Como diría Pablo Macera (1978): "La élite de criollos había jurado la República sin abjurar la conquista".

Hoy, no hay duda que la mayor insurrección indígena anticolonial fue la protagonizada por Túpac Amaru y Túpac Catari y que sus líderes locales en Tacna, Arica y Tarapacá fueron Juan Buitrón y Ambrosio Ali, (Cúneo-Vidal, 1921; Hidalgo, 2004; Cavagnaro, 2006; Panty, Choque y Ayca, 2010; Velarde y Choque, 2015). El primero nacido en el valle de Codpa y el segundo en el de Tarata. Se cuenta a Cúneo Vidal (1921) entre los primeros estudiosos de la expresión local de la rebelión; sin embargo, debido a que utilizó fuentes eminentemente españolas y debido a su tendencia historiográfica tradicional vio en este movimiento y sus líderes como una conjura contra el sistema, llamando a sus líderes como temibles "sanguinarios"; o también como Luis Cavagnaro (2006) llama en su relato "el pueblo de Tacna prepara la resistencia al ataque de los rebeldes" (énfasis nuestro), sin efectuar un análisis de las causas socioeconómicas, las fuerzas sociales en pugna, las finalidades o no usando para el propósito las estadísticas de población, o confundiendo la categoría "pueblo" para la ocasión. Como diría Jorge Hidalgo (2004) en su trabajo sobre "Las fases de la rebelión indígena en 1871" - y con quien coincidimos plenamente en este punto- "sin un estudio de las condiciones económicas no se podría explicar su origen, pero sin acudir a los factores ideológicos sería difícil entender su desarrollo". La tesis doctoral de Hidalgo (1986) sobre el levantamiento de Túpac Amaru II en la actual región norte chilena (territorio de los corregimientos de Arica y Tarapacá) es uno de los mejores aportes al respecto, al presentar información empírica que procede de diversos archivos sobre todo españoles, bolivianos y argentinos.

En este proceso revolucionario, que inicia la independencia en el Perú, fueron los campesinos, que en la medida que fue desarrollando la revolución, fueron desplazando a los otros grupos sociales, consiguiendo la hegemonía y logrando imponer reivindicaciones campesinas, en claro enfrentamiento con todo lo occidental (Flores 1987; Choy, 1988; Vega, 1999). Ellos exigían la transformación radical de la sociedad colonial. Y como añade Alberto Flores Galindo (1987), "Las masas anhelaban la vuelta a ese Tahuantinsuyo que la imaginación popular había recreado con los rasgos de una sociedad igualitaria, un mundo homogéneo compuesto solo por runas (campesinos andinos) donde no existirían ni grandes comerciantes, ni autoridades coloniales, ni haciendas, ni minas, y quienes eran hasta entonces parias y miserables volverían a decidir su destino: la imagen clásica de las revoluciones populares como la inversión de la realidad, la tortilla que se voltea, el mundo al revés" 
En el actual territorio de Tacna, en el verano del año 1781 estalló la insurrección tupacamaristatupacatarista, al mando de los capitanes Juan Buitrón y Ambrosio Ali, muy conectados inicialmente a los mandos de Cusco y luego a los de La Paz. Este movimiento indígena de Buitrón y Ali se anticipó en 30 años al movimiento criollo dado por Francisco Antonio de Zela de 1811.

Todo un proceso de guerra revolucionaria independentista precedió al levantamiento de Zela. Se dio en una coyuntura de grandes agitaciones sociopolíticas y militares en el sur occidental-andino, al que pertenecía Tacna.

En consecuencia, el gran movimiento de Túpac Amaru II resulta constituirse en una revolución popular anticolonial, por la dirección y la aglutinación de las fuerzas sociales bajo su mando, y atravesó por etapas muy marcadas. Desde sus inicios con un programa nacional anticolonial, dirigido por la aristocracia indígena, pues reunió en torno suyo a fuerzas étnico-sociales nacionales: criollas, mestizas, indígenas, negras; y se enfrentó a los peninsulares o "chapetones" de la aristocracia española, para luego ser desbordadas por las masas campesinas y convertirse en un movimiento étnico antiespañol.

A diferencia del movimiento que lideró el cacique de Tungasuca, el de Francisco Antonio de Zela, de junio de 1811, asumió un carácter autonomista (Seiner, 1995; Panty y Choque, 2010), es decir, se enfrentó al virrey, pero no contra el rey de España. Esto se debe a que cuando Zela se levantó, la Junta de Buenos Aires decidió aún no romper con España, basada en la teoría jurídica esbozada por Moreno y seguida por Castelli.

Por su parte, la rebelión de Enrique Pallardelli difiere de la de Zela, debido a su carácter separatista, anticolonial; su misión era destruir el sistema colonial español. Esto se debe a que la Asamblea Constituyente de Buenos Aires recién en 1813 acabó con su fidelidad a Fernando VII, cuando el monarca acabó con las cortes y declaró la guerra a las Juntas de América hispánica.

\section{Objetivos ideopolíticos de las insurrecciones}

Comprendiendo el carácter que le da cada enfoque histórico al movimiento, podemos colegir los objetivos que le otorgan al mismo.

El gran movimiento de Túpac Amaru representó un verdadero programa nacional anticolonial. Se enfrentó a los peninsulares "chapetones" de la aristocracia española y afirmó la necesidad de la destrucción de las instituciones coloniales: corregimiento, mita, repartos, tributo, esclavitud, entre otros.

Como toda ideología de los movimientos rebeldes se refleja en un programa político, el de Túpac Amaru II fue estructurado según Flores Galindo (1987) en tres puntos centrales:

1) La expulsión de los españoles o de los "chapetones", como acostumbraba decir despectivamente: no bastaba con suprimir los corregimientos y los repartos, deberían abolirse la Audiencia, el Virrey y romper cualquier dependencia con el monarca español.

2) La restitución del imperio incaico: fiel a la lectura del Inca Garcilaso, pensaba que podía restaurarse la monarquía incaica, teniendo a la cabeza a los descendientes de la aristocracia cuzqueña.

3) La introducción de cambios sustantivos en la estructura económica: supresión de la mita, eliminación de grandes haciendas, abolición de aduanas y alcabalas, libertad de comercio.

Los objetivos políticos de los movimientos criollos, tanto de Zela como de Paillardelle, fueron muy claros y precisos, y válidos tanto para el Bajo Perú y Alto Perú entre 1811 y 1813: contribuir a la consolidación del gobierno de las Provincias Unidas del Río de la Plata para enfrentar en mejores condiciones al ejército del virrey Abascal asentado en Lima. Dichos objetivos se basaban en el programa político republicano de Mariano Moreno de 1810 y los acuerdos de la asamblea constituyente en los años siguientes. Dicho plan contenía el principio jurídico de la retroversión de la soberanía al pueblo por la ausencia del rey y la idea del misterio -o máscara- de Fernando, que consistía en la no ruptura con España con el objetivo de acumular fuerzas para así enfrentar de mejor manera el desenlace final que traería la independencia (Moreno, 2007). Cuando en 1813, el rey restaura el monarquismo en España y declara 
abolida la Constitución liberal de 1812 sancionada por las Cortes, entonces el gobierno insurgente decide efectivizar la soberanía nacional. En esta última etapa es cuando estalla la rebelión de Paillardelle premunida de los ideales separatistas propugnadas desde Buenos Aires.

La historia tradicional sostiene que Zela buscó instaurar un verdadero régimen anticolonial, sin sopesar objetivamente las casi nulas fuerzas militares, logísticas y programáticas al respecto. De esta incomprensión resulta la tan mentada frase que el movimiento de Zela fue el "primer grito en América" (Cúneo-Vidal, 1921; Cavagnaro, 2008), lo que no es cierto. En cambio, la historia crítica sostiene que sus objetivos no podían sobrepasar los propuestos por el gobierno de las Provincias Unidas del Río de la Plata para el Bajo Perú y Alto Perú, es decir, contribuir a la consolidación de este para avanzar hacia el enfrentamiento con el ejército del virrey Abascal (Seiner, 1995; Panty y Choque, 2010).

\section{Composición social del núcleo rebeldey la alianza con otros sectores}

El programa rebelde de 1780 reclamaba el liderazgo de los curacas y los nobles incas. Pero para que estos pudieran vencer necesitaban no solo del apoyo campesino, sino también del concurso de otros sectores sociales, en especial de los criollos. Túpac Amaru II pensaba conformar un nuevo "cuerpo político", en el que convivieran armónicamente criollos, mestizos, negros e indios rompiendo con la distinción de castas y generando solidaridades internas entre todos aquellos que no fueran españoles. El programa tenía evidentes rasgos de lo que podríamos llamar un movimiento nacional (Flores, 1987).

En cuanto a la rebelión de Zela, sin presentar pruebas objetivas y convincentes, la vieja historia oficial imagina que esta tuvo una composición multiétnica. Es más, cree equivocadamente, en este punto, que solo utilizando categorías étnicas se puede reconstruir la composición social del proceso en cuestión (Cavagnaro, 2006). Creemos que, si se aspira a la objetividad del relato, es necesario además utilizar las categorías de clase (Bonilla y Spalding, 1972). Entonces podemos decir con más propiedad que fue un pequeño sector de criollos-comerciantes y hacendados locales vinculados a la arriería con el Alto Perú (Zela, Siles, Argandoña, Herrera, etc.) quienes dirigieron el movimiento, pero que necesitaron de aliados mestizos -comerciantes y arrieros como los Ara, vinculados familiarmente muchos de ellos entre sí. Un minoritario sector indígena campesino o comunero fue acampado en la pampa de Caramolle solo en el cuarto día del levantamiento (Cúneo- Vidal, 1921). Seiner (1995) subraya que los comerciantes son la columna vertebral de los núcleos rebeldes de Zela y Paillardelle, lo mismo señala Rosenblitt (2013) al decir que son los mercaderes los que coparon las “juntas autonómicas de 1811 y 1813 ”. Habría que añadir que el movimiento de Paillardelle tuvo mayores miras en la política de alianzas ya que, además de comerciantes y hacendados criollos, convocó a los indígenas campesinos ligados al comercio y demandó la liberación de la población esclava africana (Quispe, 2010).

\section{Dirección política y militar}

Dirigida por la aristocracia indígena, el ejército tupacamarista estaba formado bajo el principio de la jerarquía étnica (Sivirichi, 1979; Vega, 1981). "Los grados de capitán y comandante fueron por lo general adjudicados a criollos, mestizos y caciques indígenas. Ellos constituyeron la dirigencia militar del ejército rebelde" (O'Phelan, 1979).

Cuando se desató el levantamiento de Túpac Amaru II, los caciques tacneños -vinculados a la arriería directa o indirectamente- no apoyaron la causa libertaria, sino que estuvieron en contra como el caso de los Ara, los Cañipa, los Lupistaca y los Copaja. Entonces, frente a ese vacío de liderazgo, fueron los llamados segundas personas de los caciques o los llamados indígenas principales los que protagonizaron el levantamiento como en los casos de Juan Buitrón y Ambrosio Ali. Estos se constituyeron en los capitanes como así se consta en los apremios y llamamientos manuscritos que recorrió entre la población indígena durante la insurrección (Cúneo- Vidal, 1921; Velarde y Choque, 2015). 
$\mathrm{Al}$ atenernos de la información contendida en el Expediente formado por el alcalde de Arica José Joaquín de Oviedo sobre los sucesos del levantamiento tupacamarista-tupacatarista entre Tacna y Tarapacá en 1781, puede mencionarse al capitán general Juan Buitrón, a su lugarteniente Juan Mercado, al capitán Ambrosio Ali, a los líderes o jefes Esteban Olave, Juan Carvajal, y Miguel Reinoso. En Moquegua, se tiene a los caciques de Carumas y Ubinas como rebeldes. Las autoridades coloniales remitieron sendas expediciones a cargo de la compañía de dragones de la villa de Moquegua para pacificar esos pueblos entre abril de 1781. En cambio, se tienen como caciques fieles a los de Puquina y Torata. Se sugiere que las autoridades étnicas de Belén, opuestas al gobierno de Cañipa de Codpa desempañaron labor a favor de los rebeldes. Se tiene en este sentido a Ynquiltupa, quien ocupaba el cargo de alcalde en 1778, y Asencio Maquera, alcalde mayor en 1780, quien fue identificado como el principal del ayllu Mancasaya de Belén, en la Revisita de 1773 (Inostroza, 2011). En Socoroma ocupó el cargo de Segunda, fue Esteban Gutierres, quien participó en la ejecución del cacique Felipe Cañipa; en estos hechos de igual forma participó el sublevado segunda persona de Putre (Contreras, 1987).

En cuanto al movimiento de Zela de 1811, hubo una dirección criolla republicana, desde la Junta de Gobierno de las provincias unidas del Río de la Plata a través del emisario Castelli, y en lo local, con la dirección de un grupo de comerciantes locales, como se observó al analizar la composición social del grupo rebelde.

Mientras que la historia oficial habla de una alianza de los sectores sociales criollos, indígenas, mestizos; la historia alternativa sostiene que se trata de una rebelión típicamente criolla por los objetivos políticos esgrimidos y los cambios en la estructura política en los cortos días que duró la misma. Se refiere a los personajes que complotaron la noche del 20 de junio de 1811, y a quienes fueron designados por Zela para los cargos administrativos, políticos y militares de lo que llamó el gobierno o Comandancia de la Unión Americana. Es cierto, el programa y los bandos publicados por el líder criollo excluía de sus objetivos políticos y sociales las demandas e intereses de los sectores indígenas y negros de la ciudad.

La rebelión liderada por Paillardelle, Calderón de la Barca, José Gómez y el Cabildo tacneño, en lo local tuvo una dirección criolla republicana desde la Junta de Buenos Aires a través del emisario Manuel Belgrano. Como ya se afirmó este movimiento tuvo contenido libertario, su acción fue inmoladora y enfrentó militarmente a las fuerzas españolistas. La participación de la población en este levantamiento no fue homogénea; si bien participaron criollos, mestizos, indios, y hasta tropas regulares al servicio del rey, también, seguro algunos mulatos y hasta nativos españoles, ha existido una resistencia de los hacendados esclavistas de esta ciudad a no liberar a sus esclavos para la causa de la independencia. Por testimonio propio, Paillardelle dice: “...intenté dar la libertad á los Negros, lo que no pude verificar á causa de que algunos malbados me amotinaron la Gente, y no pudiendo castigar á estos por no tener como sostener mis determinaciones, me fue imposible tomar medidas para apoderarme del resto de la Costa" (Choque y Quispe, 2013).

\section{CONCLUSIONES}

El proceso de las insurrecciones desarrollado durante la crisis del régimen colonial español, en el territorio de lo que fue los corregimientos de Tarapacá y Arica, tiene un punto resaltante con la revolución de José Gabriel Condorcanqui (Túpac Amaru II) de 1780-1781. La narrativa liberal tradicional vio en este movimiento una conjura contra el sistema colonial; mientras que la nueva historia sostiene que con este se inicia una coyuntura de ruptura radical -como parte del movimiento nacional indígena- contra el sistema imperante, lo que configura sus objetivos ideopolíticos. Según sus objetivos ideopolíticos, la rebelión de Zela, anticipada 30 años, constituye una rebelión autonomista-reformista; y la de Paillardelle, uno de signo separatista; sin embargo, estas dos últimas dentro del movimiento de liberación criollo vinculado a comerciantes y hacendados provincianos y a la Junta de Gobierno de las provincias unidas del Río de la Plata. 
La composición social del núcleo rebelde de 1780 involucró a los curacas y los nobles incas. Pero necesitaron no solo del apoyo campesino y los esclavos, sino también del concurso de los criollos. Las rebeliones de Zela y Paillardelle congregaron a terratenientes y comerciantes criollos fundamentalmente. Fueron estos sectores del núcleo rebelde quienes asumieron el liderazgo y la dirección política y militar.

Respecto a los alcances y límites en el proceso de la independencia en la región, el país y el continente, se puede señalar que doscientos años después del período insurgente, la sociedad nacional y latinoamericana se estremece con una grave crisis general que cuestiona las bases de la formación social impuesta por los independizadores y fundadores de la República; esto, precisamente, porque la naciente formación no supo resolver los grandes problemas nacionales. Ello invita a los equipos de académicos e investigadores a profundizar los estudios del pasado en Latinoamérica; a la par de brindar los resultados de estas investigaciones para la reorientación y reconstrucción de los Estados Nacionales, como parte del proceso emergente del gran Estado Latinoamericano, verdaderamente democrático, soberano y con bienestar general.

\section{REFERENCIAS}

Bonilla, H. y Spalding, K. (1972). La Independencia en el Perú: Las palabras y los hechos. En Bonilla, Heraclio, y otros., La Independencia en el Perú. Lima: Instituto de Estudios Peruanos.

Cavagnaro, L. (2006). Materialespara la historia de Tacna. T. V. Imp. Tacna: Perugrafica.

Cavagnaro, L. (2008). Zela, adalid de la libertad. Tacna: Imp. Perugrafica.

Contreras, J. (1987). Los kurakas del desierto de Arica, Tarapacá, siglos XVI-XVIII (Tesis de Historia y Geografía). Universidad de Tarapacá. Arica, Chile.

Cúneo-Vidal, R. (1921). Historia de las insurrecciones de Tacna por la independencia del Perú. Lima: Librería e imprenta Gil.

Choque, E. y Quispe, F. (2013). “La rebelión de Tacna de 1813. Archivo, (1), Tacna.

Choy, E. (1988) [1954]. Sobre la revolución de Túpac Amaru. En Choy, E. Antropología e historia 3. Lima: Editorial de la Universidad Nacional Mayor de San Marcos.

Flores, A. (1987). (Compilador) Independencia y revolución. Lima: T.I INC editores.

Hidalgo, J. (1986). Indian Society in Arica, Tarapaca and Atacama, 1750-1793 and its response to the rebelion of Tupac Amaru. En Contreras, J. y otros. (1987). Los kurakas del desierto de Arica, Tarapacá, siglos XVI-XVIII. Universidad de Tarapacá. Arica, Chile.

Hidalgo, J. (2004). Historia andina en Chile. Santiago de Chile: Editorial Universitaria.

Hidalgo, J. (2004). La revisita de Codpa (altos de Arica) de 1772-73 efectuada por el corregidor Demetrio Egan. Chungara, Revista de Antropología Chilena, 36(1), 103-204.

Inostroza, X. (2011). Diferenciación social y liderazgo en Comunidades andinas: los principales" de Belén y Socoroma: 1750-1799. Corregimiento de Arica. Diálogo Andino (38), 35-43.

Macera, P. (1978). Visión histórica del Perú. (Delpaleolitico alproceso de 1968). Lima: Edit. Milla Batres.

Moreno, M. (2007) [1954]. Plan de Operaciones. Buenos Aires: Biblioteca Nacional.

O'Phelan, S. (1979). La rebelión de Túpac Amaru: organización interna, dirigencia y alianzas. Histórica, III (2).

Panty, O., Choque, E. y Ayca, O. (2010). Historia de laprovincia Jorge Basadre. Tacna: Edit. Perugrafica.

Panty, O. y Choque, E. (2010). Francisco Antonio de Zela, elpersonaje en el contexto. Tacna: Edit. Perugrafica.

Quispe, F. (2010). Una lectura de la historia de Tacna. Enrique Paillardelle: peregrino, patriota y conspirador. Buenos Aires.

Rosenblitt, J. (2013) Centralidad geográfica, marginalidad política: La región de Tacna-Arica y su comercio, 1778-1841. Santiago: Ediciones de la Dirección de Bibliotecas, Archivos y Museos. 
Objetivos e intereses de las insurrecciones tacneñas durante la crisis del régimen colonial español 17801813

Seiner, L. (1995). Francisco Antonio de Zela. Lima: Edit. Brasa.

Sivirichi, A. (1979).La revolución social de los Túpac Amaru. Lima: Editorial Universo.

Vega, J. (1981). Historia general del ejército peruano. El ejército durante la dominación española del Perú. Tomo III. Vol.

2. Campañas militares durante la dominación española. Lima: CPHEP.

Vega, J. (1999). La revolución indígena de Túpac Amaru II. La República (Lima).

Velarde, M. y Choque, E. (2015). La revolución de Túpac Amaru y Túpac Catari en Tacna. Tacna: Imprenta Gráfica. 